\title{
Infectious Encephalomyelitis
}

National Cancer Institute

\section{Source}

National Cancer Institute. Infectious Encephalomyelitis. NCI Thesaurus. Code C79551.

An infectious process that affects the brain and spinal cord tissues. It is usually caused by viruses. 